
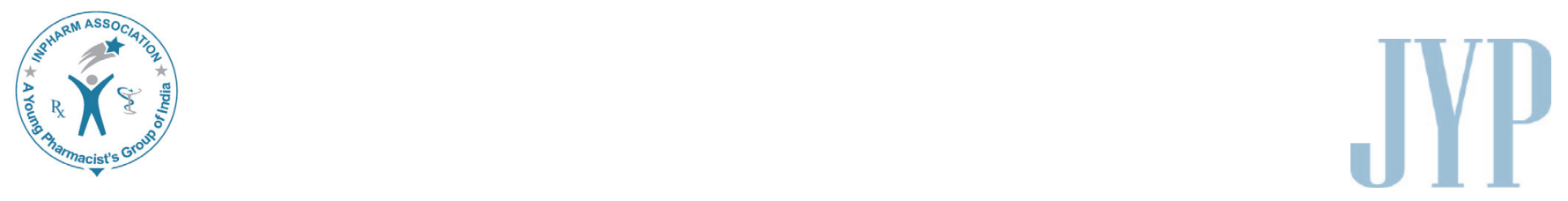

\title{
Saroglitazar, a novel cardiometabolic agent for diabetic dyslipidemia - A Review
}

\author{
Arun Sharma ${ }^{1 *}$, S Amarnath ${ }^{1}$, Devendra Singh Kushwah², S Ramaswamy¹ \\ ${ }^{1}$ Department of Pharmacology, Sri Lakshmi Narayana Institute of Medical Sciences, Puducherry - 605502, \\ India. \\ ${ }^{2}$ Department of Pharmacology, Netaji Subash Chandra Bose Medical College \& Hospital, Jabalpur- \\ 482003, India.
}

\begin{abstract}
Diabetes mellitus is a worldwide prevalent chronic disease with a significant disease burden. The associated dyslipidemia adds to the lethality of type 2 diabetes mellitus and requires newer and better treatment strategies. Peroxisome proliferator activated receptor (PPAR) $\alpha$ and $y$ agonists are approved hypolipidemic and anti-diabetic agents respectively and combining them together provides a dual benefit in type 2 diabetes mellitus associated with dyslipidemia. This novel class of dual PPAR agonists are termed as "Glitazars" and in 2013, Saroglitazar, a member of this class of drugs; was approved by the Indian regulatory authority Drug Controller General of India (DCGI) for the treatment of diabetic dyslipidemia. It is the first glitazar to gain regulatory approval anywhere in the world and is also the first New Chemical Entity (NCE) to be discovered in India. This review provides an overview of this novel drug including its mechanism of action and prospective uses.
\end{abstract}

Key words: Diabetic dyslipidemia, Glitazars, PPAR agonists, Type 2 diabetes.

\section{INTRODUCTION}

Type 2 diabetes mellitus is a chronic disease with a marked influence on the quality of life and a significant global presence. The number of diabetes patients in India is estimated to reach 68 million by the year $2025 .{ }^{1}$ In this

\begin{tabular}{|c|l|}
\hline \multicolumn{2}{|c|}{ Access this article online } \\
\hline \multirow{2}{*}{ Journal Sponsor } & \\
\hline & $\begin{array}{l}\text { Website: } \\
\text { www.jyoungpharm.org }\end{array}$ \\
\cline { 2 - 3 } www.phcog net & $\begin{array}{l}\text { DOI: } \\
\text { 10.5530/jyp.2015.1.2 }\end{array}$ \\
& \\
\hline
\end{tabular}

setting, it is necessary to continue ongoing research to develop newer anti-diabetic drugs to achieve good control of the disease and to monitor the existing drugs for their side effects. Despite, the disease related mortality remains quite high.

The most common cause of mortality in type 2 diabetes mellitus is cardiovascular disease, ${ }^{2}$ mainly due to the atherosclerotic macrovascular changes resulting in myocardial infarction. These events are linked to the diabetic dyslipidemia, which is defined by the presence of an altered lipid profile in a diabetic patient, and characterized by elevated serum triglyceride (TG) levels $(>150 \mathrm{mg} / \mathrm{dL})$,

*Address for correspondence:

Dr. Arun Sharma, Department of Pharmacology, Sri Lakshmi Narayana Institute of Medical Sciences, Puducherry - 605502, India,

Email: drarun86md@gmail.com 


\section{Ragaglitazar (NN 622)}

TAK-559

Sipoglitazar

Muraglitazar

Cevoglitazar

Tesaglitazar

Aleglitazar
Dr. Reddy / Novo Nordisk (Discontinued in 2003 over bladder cancer concerns in rodent models)

Takeda (Discontinued in 2005)

Takeda (Discontinued in 2006)

Bristol Myers Squibb (Discontinued after phase III trials in 2006 due to $\uparrow$ incidence of heart failure)

Novartis (Discontinued in 2008)

Astra Zeneca (Discontinued after phase III trials in 2006 due to renal and bone marrow toxicity)

Hoffman-La-Roche (Discontinued after phase III trials in 2013) reduced high-density lipoprotein (HDL) cholesterol levels $(<40 \mathrm{mg} / \mathrm{dL}$ in males and $<50 \mathrm{mg} / \mathrm{dL}$ in females) and normal or elevated levels of low-density lipoprotein (LDL) cholesterol $(>100 \mathrm{mg} / \mathrm{dL}) .{ }^{3}$ Several studies have shown that intensive glycemic control has little or no effect on preventing macrovascular complications. ${ }^{4,5}$ Thus, a lot of emphasis has been laid to control diabetic-dyslipidemia in order to reduce the macrovascular complications and eventually, to reduce the mortality rates.

The role of peroxisome proliferator-activated receptor (PPAR) agonists in the treatment of type 2 diabetes mellitus patients to reduce the cardiovascular risk has long been an area of ongoing medical research. The three PPAR receptors (PPAR- $\alpha$, PPAR- $\beta$ and PPAR- $-\gamma$ ) form a subfamily of nuclear receptors. They function as lipid sensors and regulate the expression of a large number of genes associated with metabolism. These PPARs form a heterodimer with a nuclear receptor called the retionid X receptor (RXR), which in turn binds to peroxisome proliferator response elements (PPREs) located within the target genes. ${ }^{6}$ PPAR- $\alpha$ activators (fibrates e.g. Clofibrate) are commonly used to treat dyslipidemia owing to their property to decrease triglyceride levels and increase HDL cholesterol levels. ${ }^{7}$ Additionally, they also promote cholesterol efflux from the macrophages. ${ }^{8}$ In several clinical studies, PPAR- $\alpha$ activators have shown to reduce the incidence and progression of atherosclerosis thereby improving cardiovascular health. ${ }^{9}$ PPAR- $\beta$, known as PPAR- $\delta$, is expressed widely but its exact pharmacological actions are poorly understood. PPAR- $\gamma$ is also expressed in a wide variety of tissues, with highest concentration being in adipose tissue. ${ }^{10}$ It promotes lipid deposition in adipocytes and plays an important role in adipocyte differentiation process. ${ }^{11}$ PPAR $-\gamma$ agonists (thiazolidinediones) are approved for glycemic control in type 2 diabetes due to their reversal of lipidotoxicity mechanisms and reduced secretions of inflammatory cytokines and chemokines, ultimately decreasing insulin resistance. ${ }^{12,13}$ In experimental animal models, PPAR $-\gamma$ agonists have demonstrated several cardiovascular benefits. ${ }^{14,15}$ However, in humans a clear demonstration of reduction in cardiovascular disease is yet to be seen.

Journal of Young Pharmacists Vol 7 • Issue 1 • Jan-Mar 2015
Based on their pharmacological actions, several combined PPAR $-\alpha$ and PPAR $-\gamma$ therapeutic regimens (fibrates and glitazones) have been evaluated in recent years for treatment of type 2 diabetes mellitus. ${ }^{16,17}$ While the results were encouraging, clear cut therapeutic benefit could not be established and large scale trials are still lacking. Taking research in this field one step further, several pharmaceutical organizations have developed and clinically tested dual PPAR agonists (compounds with dual PPAR$\alpha$ and PPAR- $\gamma$ activity, also called "Glitazars") following promising results in animal studies. However, most of these compounds have been not been successful primarily due to their profound side effects.

\section{SAROGLITAZAR: FIRST GLITAZAR TO GAIN REGULATORY NOD}

Saroglitazar is a novel glitazar compound developed indigenously in India and gained regulatory approval from the Indian regulatory authority DCGI in June $2013 .{ }^{18}$ It was developed by Zydus Cadilla and is available under the trade name Lipaglyn ${ }^{\mathrm{TM}}$. It is also the first member of the glitazar class to gain approval anywhere in the world and is also the first NCE (New Chemical Entity) to be discovered in India. It was developed with the aim of optimizing the beneficial anti-dyslipidemic and anti-glycaemic effects while minimizing the harmful side effects that plagued the other members of this class. ${ }^{19}$ (Figure 1)

\section{Chemical structure and Mechanism of action}

The chemical name for Saroglitazar is $(\alpha \mathrm{S})-\alpha$-Ethoxy-4[2-[2-methyl-5-[4-(methylthio) phenyl]-1H-pyrrol-1-yl] ethoxy] benzenepropanoic Acid. (Figure 2)

Empirical formula - $\left[\mathrm{C}_{25} \mathrm{H}_{28} \mathrm{NO}_{4} \mathrm{~S}\right]_{2} \mathrm{Mg}$

Molecular mass - $900 \mathrm{~g} /$ mole

Dosage form - Available as a $4 \mathrm{mg}$ tablet

Saroglitazar is a dual PPAR activator with predominant 


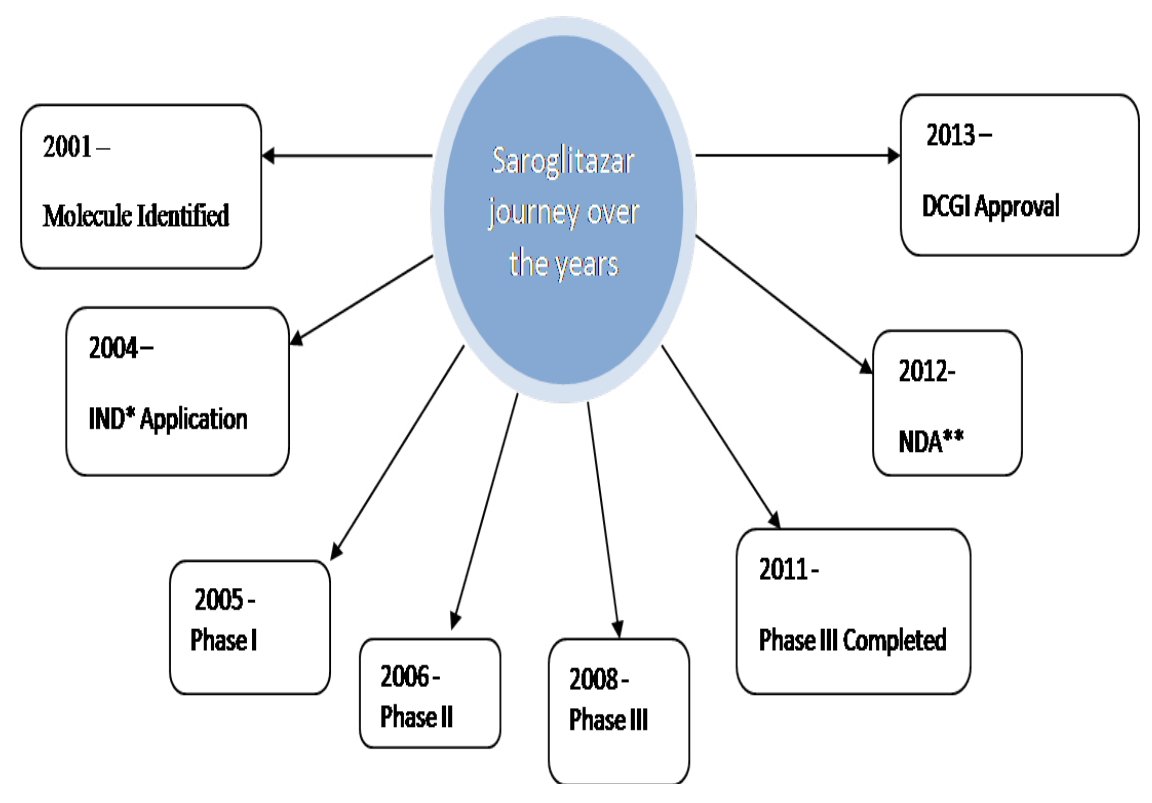

Figure 1: Journey of Saroglitazar from conception to market

* IND - Investigational New Drug : ** NDA- New Drug Application

PPAR $-\alpha$ and moderate PPAR $-\gamma$ agonist action. PPAR- $\alpha$ activation increases the fatty acid oxidation process in the liver and also reduces secretion of triglycerides and VLDL (very low density lipoproteins) which promotes fatty acid uptake by liver, thus decreasing fatty acid synthesis and peripheral triglyceride levels. It also activates lipoprotein lipase and decreases production of apolipoprotein C-III (inhibitor of lipoprotein lipase) thereby promoting lipolysis. There is also increase in synthesis of apolipoprotein A-I, A-II and HDL-C (high density cholesterol) and a reduction in inflammation.

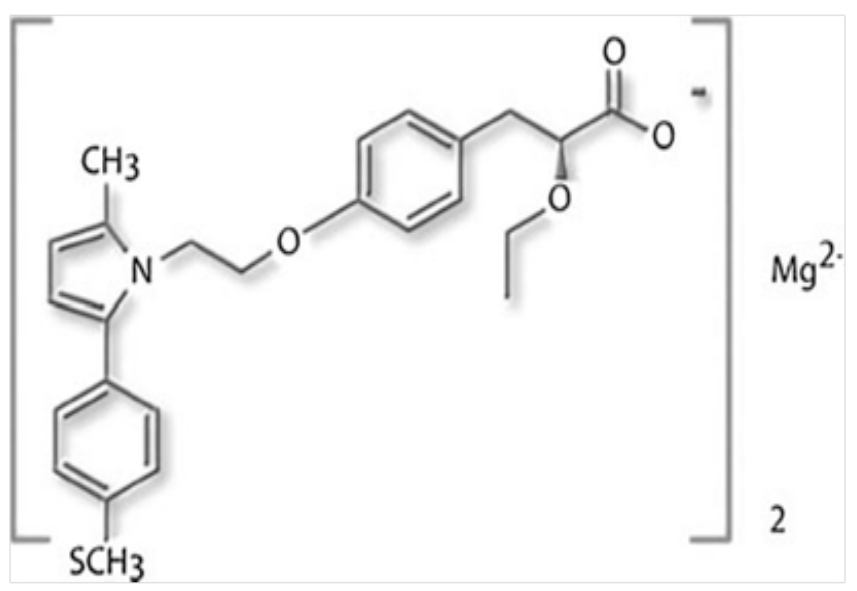

Figure 2: Saroglitazar: structural formula
Saroglitazar, via PPAR- $\gamma$ activation, activates the genes involved in glucose metabolism (adiponectin, CD 36 etc.) and increases the insulin sensitivity, glucose uptake and utilization. It also increases fatty acid uptake and decreases post-prandial surge in their levels. As a result, metabolic burden on liver and muscle is reduced. ${ }^{20}$

\section{Clinical Pharmacokinetics}

Saroglitazar is rapidly absorbed following oral route of administration and peak plasma levels occur at $1 \mathrm{hr}$ after the dose. In a single ascending dose study $(0.125,0.25,0.5,1,2$, $4,8,16,32,64$ and $128 \mathrm{mg}$ ) of saroglitazar in healthy human volunteers, it was well absorbed across all the dosages with a $t_{\text {max }}$ of less than $1 \mathrm{hr}$ and maximum plasma concentration ranging from 3.98 to $7,461 \mathrm{ng} / \mathrm{mL}$ across the dose ranges studied. ${ }^{19}$ Maximum plasma concentration $\left(\mathrm{C}_{\max }\right)$ and area under the curve $\left(\mathrm{AUC}_{0-\infty}\right)$ of saroglitazar increased with increased dosage in a dose dependent manner. The mean elimination half life $\left(t_{1 / 2}\right)$ of saroglitazar was found to be 5.6 $\mathrm{hr}$ across all the doses and combined analysis of male and female healthy volunteers showed no significant gender or food effect on the pharmacokinetic parameters. However, terminal half life was found to be significantly shorter in females than their male counterparts.

Saroglitazar is chiefly eliminated in an unchanged form by the hepato-biliary route, without involving the renal route. ${ }^{21}$ This is beneficial in patients with advanced stage of type 2 diabetes mellitus with renal compromise as no 
dose adjustments are required for saroglitazar in these patients. In vitro saroglitazar shows high protein binding $(\sim 96 \%)$ in human plasma. Considering the half life and on the basis of several multiple-dose studies in humans, saroglitazar does not show any potential for accumulation on once-daily repeat dosing.

\section{Pre-Clinical toxicology}

In various acute and chronic toxicity studies on mice, rats and dogs for a 12 month period, no adverse changes were noted in central nervous system, cardiovascular system, gastrointestinal and respiratory system. ${ }^{20}$ Saroglitazar was found to possess an acceptable safety profile even at doses several times higher than the approved human dose of $4 \mathrm{mg}$. Doses as high as $3 \mathrm{mg} / \mathrm{kg}$ up to $125 \mathrm{mg} /$ $\mathrm{kg}$ did not adversely affect mating/fertility behavior in female rats and male rats respectively. Developmental studies failed to indicate any significant adverse effect on reproductive performance and lactating indices up to a dose of $1 \mathrm{mg} / \mathrm{kg}$. A two year carcinogenicity study in Wistar rats, followed by a mechanical study in non-human primates employing molecular biomarkers revealed no potential concern for cancer in humans. Embryonic-fetal developmental studies done in pregnant rats failed to show any significant maternal or fetal toxicity at higher doses (up to 12 times than the human recommended dose). Genetic toxicological studies like Ames mutagenecity test and mouse micronucleus assay showed saroglitazar to be non-mutagenic and non-genotoxic. ${ }^{20}$

\section{Efficacy and Indications}

Saroglitazar is indicated mainly for type 2 diabetes mellitus patients for the treatment of diabetic dyslipidemia and hypertriglyceridemia not controlled by statin therapy. The recommended regimen is of one tablet of $4 \mathrm{mg}$ taken once-daily.

Saroglitazar has shown significant reduction of triglycerides, LDL cholesterol, Very Low Density Lipoprotein (VLDL) cholesterol, non - High Density Lipoprotein (non- HDL) cholesterol and an increase in HDL cholesterol in clinical studies. ${ }^{20,22}$ It has also shown good reduction in fasting plasma glucose (FPG) and glycosylated hemoglobin (HbA1 $1_{c}$ levels. In a Prospective Randomized Efficacy and Safety of Saroglitazar (PRESS V) study of 24 weeks duration, Saroglitazar produced a dose-related (45\%) reduction in triglyceride levels, which was higher than the decline in levels reported with fenofibrate (29-36\%). ${ }^{22}$ Saroglitazar $4 \mathrm{mg}$ was also superior to pioglitazone $45 \mathrm{mg}$ in reducing total cholesterol, LDL-C and VLDL-C while the effects on HDL-C, apolipoprotein A1, apolipoprotein B, FPG and $\mathrm{HbA} 1_{\mathrm{c}}$ were comparable with both drugs.
The adverse events reported with saroglitazar $4 \mathrm{mg}$ were asthenia, gastritis, chest discomfort, dizziness and tremors and were mostly of mild intensity. No serious adverse event (SAE) and no side effects like peripheral edema and weight gain were observed in the saroglitazar arm. Also, the number of patients achieving the target lipid levels as per the Adult Treatment Panel III (ATP III) criteria of US National Cholesterol Educational Program was significantly higher with saroglitazar $4 \mathrm{mg}$ as compared to pioglitazone $45 \mathrm{mg} .^{22}$

Similarly, in a 16-week prospective, multicenter, randomized, double-blind, placebo controlled, three-arm Phase III study on type 2 diabetes mellitus patients with hypertriglyceridemia ( $>200 \mathrm{mg} / \mathrm{dl}$ and $<500 \mathrm{mg} / \mathrm{dl}$ ) and already taking atorvastatin $10 \mathrm{mg}$, subjects were treated with $2 \mathrm{mg}$ and $4 \mathrm{mg}$ saroglitazar for a period of 12 weeks after a 4 week washout period and life-style modifications. Both the saroglitazar arms (saroglitazar $2 \mathrm{mg} /$ day + atorvastatin and saroglitazar $4 \mathrm{mg} /$ day + atorvastatin) showed significant reduction in triglycerides $(-45.5 \pm 3.03 \%$ and $-46.7 \pm 3.02 \%$ respectively in $2 \mathrm{mg}$ and $4 \mathrm{mg}$ arms) as compared with the third control arm (placebo + atorvastatin). ${ }^{23}$ There was a significant decrease in levels of non-HDL-C, very LDL-C, total cholesterol and FPG in saroglitazar $2 \mathrm{mg}$ arm while an additional decrease in LDL-C and apolipoprotein B levels was also observed in saroglitazar $4 \mathrm{mg}$ arm. A reduction in $\mathrm{HbA} 1_{c}$ level was also observed in both the saroglitazar arms but it was considered non-significant statistically. At the end of 24 week time point, there was no incidence of any significant adverse events..$^{23,24}$

\section{Adverse effects and Precautions}

Gastritis, asthenia and pyrexia are the most frequent adverse effects reported in clinical trials and most of them were mild in intensity. In vitro studies done by using human cytochrome P-450 isozymes did not reveal any potential for clinically significant drug interactions with other drugs. Though considered safe, saroglitazar should be given with caution in patients with hepatic or renal impairment. Besides, when used in patients with cardiac disease, monitoring of diabetic patients for the development of congestive cardiac failure is suggested. ${ }^{20}$

\section{Use in special populations}

Safety of saroglitazar in pregnant women has not been evaluated at present though pre clinical data from studies done on pregnant rabbits show no maternal/fetal toxicity and no risk of teratogenecity. So, its use in pregnant women should only be reserved for situations where benefit from use outweighs the potential risk to fetus. Similarly, use of saroglitazar should be avoided in nursing mothers because 
it remains unclear whether it is excreted into the breast milk or not. In geriatric age groups, saroglitazar therapy should be initiated with caution keeping in mind the pre-existing co morbid conditions and the potential risk of drug-drug interactions due to concomitant medications. Safety and efficacy of using saroglitazar therapy in pediatric age group remains unverified at present and should be avoided.

\section{CONCLUSION}

Saroglitazar was conceptualizd and developed keeping in mind the needs of type 2 diabetes patients suffering from dyslipidemia and not controlled by statin therapy. Its dual mode of action provides dual benefit in dyslipidemia and hyperglycemia, thereby reducing the pill burden on the patient and improving compliance to therapy. It has shown encouraging results in various phases of clinical trials with overall good efficacy and acceptable safety profile. Saroglitazar use so far has not been associated with any serious adverse events exhibited by its predecessors (Aleglitazar, Muraglitazar etc.) and it also lacks the traditional adverse effects of weight gain and edema associated with thiazolidinediones. A non-renal route of elimination makes saroglitazar safe to be used in type 2 diabetes patients with renal compromise, however with caution. Its development and subsequent approval by the DCGI has given a boost to the Indian pharmaceutical industry. However, it is need of the hour to exercise pharmacovigilance to monitor long term clinical data before saroglitazar could be declared a safe and effective drug.

\section{COMPETING INTERESTS}

The authors declare that they have no competing interests.

\section{AUTHORS' CONTRIBUTIONS}

Article was conceived by AS and written equally by all contributing authors. All the authors read and approved the final manuscript.

\section{REFERENCES}

1. Joshi SR. Management of Obese Indian Patient. Indian Journal of Obesity. 2005; 1(1): 11-20.

2. Morrish NJ, Wang SL, Stevens LK, Fuller JH, Keen H. Mortality and causes of death in the WHO Multinational Study of Vascular Disease in Diabetes. Diabetologia. 2001; 44(2): S14-S21.

3. American Diabetes Association Clinical Practice Recommendation. Dyslipidemia management in adults with diabetes. Diabetes Care. 2004; 27(1): S68-S71.

4. Robert GD, Graham TM. Intensive glycemic control in the ACCORD and ADVANCE trials. N Engl J. Med. 2008; 358(24): 2630-33.

5. Sophia Z, Bastiaan EG, Toshiharu N, Diederick G, Pavel H, Simon H, et al. Combined effects of routine blood pressure lowering and intensive glucose control on macrovascular and microvascular outcomes in patients with type 2 diabetes new results from the ADVANCE trial. Diabetes Care. 2009; 32(11): 2068-74.

6. Desvergne B, Wahli W. Peroxisome proliferator-activated receptors: nuclear control of metabolism 1. Endocr Rev. 1999; 20(5): 649-88.

7. Plutzky J. Emerging concepts in metabolic abnormalities associated with coronary artery disease. Curr Opin Cardiol. 2000; 15(6): 416-21.

8. Chinetti G, Lestavel S, Bocher V, Remaley AT, Neve B, Torra IP, et al. PPAR- $\alpha$ and PPAR-y activators induce cholesterol removal from human macrophage foam cells through stimulation of the ABCA1 pathway. Nat Med. 2001; 7(1): 53-8.

9. Monique $\mathrm{H}$, Cawthorne MA. Dual Acting and Pan-PPAR Activators as Potential Anti-diabetic Therapies. In: M. Schwanstecher editor. Diabetes - Perspectives in Drug Therapy (Handbook of Experimental Pharmacology 203) XIV edition. Berlin Heidelberg: Springer-Verlag. 2011; 35-51.

10. Fajas L, Auboeuf D, Raspe E, Schoonjans K, Lefebvre AM, Saladin R, et al. The organization, promoter analysis, and expression of the human PPAR gamma gene. J. Biol Chem. 1997; 272(30): 18779-89.

11. Tontonoz P, Hu E, Spiegelman BM. Stimulation of adipogenesis in fibroblasts by PPAR y 2, a lipid-activated transcription factor Cell. 1994; 79(7): 1147-56.

12. Vamecq J, Latruffe N. Medical significance of peroxisome proliferator-activated receptors. The Lancet. 1999; 354(9173): 141-8.

13. Spiegelman BM. PPAR-y: adipogenic regulator and thiazolidinedione receptor. Diabetes. 1998; 47(4): 507-14.

14. Li AC, Brown KK, Silvestre MJ, Willson TM, Palinski W, Glass CK. Peroxisome proliferator-activated receptor gamma ligands inhibit development of atherosclerosis in LDL receptor-deficient mice. J. Clin Invest. 2000; 106(4): 523-31.

15. Chen Z, Ishibashi S, Perrey S, Osuga J, Gotoda T, Kitamine T, et al. Troglitazone inhibits atherosclerosis in apolipoprotein E-knockout mice: pleiotropic effects on CD36 expression and HDL. Arterioscler Thromb Vasc Biol. 2001; 21(3): 372-77.

16. Bajaj M, Suraamornkul S, Hardies LJ, Glass L, Musi N, DeFronzo R. Effects of peroxisome proliferator-activated receptor (PPAR)- $\alpha$ and PPAR-y agonists on glucose and lipid metabolism in patients with type 2 diabetes mellitus. Diabetologia. 2007; 50(8): 1723-31.

17. Boden G, Homko C, Mozzoli M, Zhang M, Kresge K, Cheung P. Combined use of rosiglitazone and fenofibrate in patients with type 2 diabetes: prevention of fluid retention. Diabetes. 2007; 56(1): 248-55.

18. Zydus pioneers a breakthrough with Lipaglyn, India's first NCE to reach the market. 2013 June [cited 2014 July 10]. Available from [http://www.zyduscadila. com/press/PressNote05-06-13.pdf]

19. R.H. Jani, K. Kansagra, M.R. Jain, H. Patel. Pharmacokinetics, Safety, and Tolerability of Saroglitazar (ZYH1), a Predominantly PPAR-a Agonist with Moderate PPAR-y Agonist Activity in Healthy Human Subjects. Clin Drug Investigation. 2013; 33(11): 809-16.

20. Lipaglyn-PI Booklet. [Cited 2014 July 10]. Available from [http://www.lipaglyn. com/downloads/Lipaglyn_PI_Booklet.pdf]

21. Sonu S. Biliary excretion of ZYH1 in Wistar rats. Ahmedabad: Cadila Healthcare Ltd. 2004.

22. Pai V, Paneerselvam A, Mukhopadhyay S, Bhansali A, Kamath D, Shankar V, et al. A Multicenter, Prospective, Randomized, Double-blind Study to Evaluate the Safety and Efficacy ofSaroglitazar 2 and $4 \mathrm{mg}$ Compared to Pioglitazone $45 \mathrm{mg}$ in Diabetic Dyslipidemia (PRESS V). J. Diabetes Sci Technol. 2014; 8(1): 132-41

23. Jani RH, Pai V, Jha P, Jariwala G, Mukhopadhyay $S$, Bhansali A, et al. A multicenter, prospective, randomised, double blind study to evaluate the safety and efficacy of saroglitazar 2 and $4 \mathrm{mg}$ compared with placebo in type 2 diabetes mellitus patients having hypertriglyceridemia not controlled on atorvastatin therapy (PRESS VI). Diabetes Technol \& Ther. 2014; 16(2): 63-71.

24. Munigoti SP, Harinarayan CV. Role of Glitazars in atherogenic dyslipidemia and diabetes: Two birds with one stone? Indian J. Endocr \& Metab. 2014; 18(3): 283. 